\title{
POLÍTICAS PÚBLICAS URBANAS DE TRANSPORTES: UMA ANÁLISE DO PROJETO ROTA VIÁRIA NA AVENIDA BERNARDO VIEIRA EM NATAL-RN
}

\section{G. G. Nascimento}

Instituto Federal de Educação, Ciência e Tecnologia do Rio Grande do Norte / IFRN (Campus Central)

E-mail: gersongomes2003@yahoo.com.br

\section{RESUMO}

O objetivo, deste trabalho, se constituiu em analisar a organização socioespacial desta avenida após sua transformação no ano de 2007-2009 via políticas públicas urbanas de transportes, levando em consideração a grande desorganização do fluxo de veículos nesta. Aplicamos formulários com quatro atores diretamente envolvidos nessa questão: os motoristas de ônibus, os transeuntes da avenida, os comerciantes e os motoristas de carros particulares bem como consultamos também órgãos municipais (SEMURB e STTU). Concluímos que tais transformações, a maneira como foram executadas não agradou nem tampouco solucionou os graves problemas socioespaciais ali existentes tais como: roubos, poluição sonora, falta de estacionamento, perda de consumidores, congestionamentos entre outros.

PALAVRAS-CHAVE: Políticas Públicas Urbanas, Organização socioespacial, Serviços.

\section{URBAN TRANSPORT PUBLIC POLICY: AN ANALYSIS OF THE PROJECT IN THE AVENUE ROAD ROUTE BERNARDO VIEIRA IN NATAL-RNABSTRACT}

\begin{abstract}
The aim of this work was constituted to examine the sociospatial organization of this avenue after his transformations years of 2007-2009 saw urban public transport policy, taking into consideration the great disruption of the flow of vehicles on this avenue. We apply four forms directly involved in this issue: bus drivers, passersby avenue, traders and drivers of private
\end{abstract}

cars and also consulted with municipal bodies (SEMURB and STTU). We conclude that such transformations, how pleased were not executed nor solved the serious problems that exist there sociospatial such as thefts, noise, lack of parking, loss of customers, among other jams.

KEYWORDS: Urban Public Policy, Organization Sociospatial, Services. 


\section{POLÍTICAS PÚBLICAS URBANAS DE TRANSPORTES: UMA ANÁLISE DO PROJETO ROTA VIÁRIA NA AVENIDA BERNARDO VIEIRA EM NATAL-RN}

\section{INTRODUÇÃO}

A Avenida Bernardo Vieira com seus $5 \mathrm{~km}$ de extensão ${ }^{1}$ constitui, na atualidade, uma das mais importantes avenidas de Natal, no que se refere ao comércio e serviços, em face da sua ligação com toda a cidade, principalmente, com uma das áreas que mais cresce em Natal, que é a Zona Norte. Até 2007, esta era a principal via de ligação à Igapó, na Zona Norte da cidade, passando pela ponte sobre o rio Potengi. Hoje, é um importante eixo viário dentro da "trama" urbana da cidade, principalmente, por está situada de forma perpendicular a outros grandes eixos viários, como as avenidas Salgado Filho, Prudente de Moraes entre outras, tornando-se uma via de grande importância e entroncamento viário principalmente pelos variados tipos de serviços que ali se concentram.

Todavia, esta importância só pode ser compreendida quando consideramos alguns aspectos e fatores relevantes ocorridos na cidade ao longo de seu crescimento. Quando da inserção de Natal na Segunda Guerra Mundial, esta avenida era mais conhecida como Avenida 15, num plano de avenidas que, segundo Lima (2003), tinha a função, apenas, de ligar as bases militares existentes na cidade em decorrência da guerra. Entretanto, em 1968, com o advento do Plano Diretor da Cidade, denominado de Plano de Sistematização de Natal (PSN), na administração do então prefeito Agnelo Alves, através da Lei número 2.211, a cidade foi organizada até a Avenida Capitão Mor Gouveia, então, área de expansão urbana. Neste contexto, outras avenidas, como a Bernardo Vieira, também, seriam contempladas com infraestrutura básica, com o objetivo de dotá-las de melhor equipamento urbano.

Anteriormente a este período (1950/1960), esta avenida se constituía, na sua maior parte, de casas populares, distantes ainda do centro (Ribeira e Cidade Alta) com pouquíssimos serviços e infraestrutura bastante precária, pois, até então, para a construção de algumas vias importantes na cidade, foi aproveitado o traçado já existente no Plano da Cidade Nova, do início do século, cuja ocupação já se consolidara. Entretanto, o prolongamento e consolidação desta avenida, como de outras nesse período, orientou o surgimento de novas localizações, direcionando parte do crescimento da cidade para todas as áreas da cidade a exemplo da Avenida Bernardo Vieira localizada na zona leste-oeste da cidade.

\section{AVENIDA BERNARDO VIEIRA: CONSIDERAÇÕES GERAIS}

\footnotetext{
${ }^{1}$ A Avenida Bernardo Vieira tem início junto ao viaduto da Urbana, no encontro com a Avenida Napoleão Laureano no bairro das Quintas na região Oeste da cidade, prolongando-se por $5 \mathrm{~km}$ até o limite do Parque das Dunas no bairro de Nova Descoberta na Zona Sul de Natal.
} 
A Avenida Bernardo Vieira no começo da década de 1970, já se constituía como uma das grandes e promissoras via de ligação entre os bairros que por ela se formavam ${ }^{2}$ e a Zona Norte que abrigava, em sua grande maioria, uma população que trabalhava em vários setores da economia da cidade, destacando-se o polo têxtil. Uma das maiores fábricas instaladas em Natal, nesse período, mais precisamente nesta avenida, era a Confecções Guararapes, da família Rocha, vindo a fechar suas portas na década de 1980. Hoje, em seu lugar, se localiza o maior shoppingcenter da cidade, o Midway Mall.

A partir das décadas de 1980 e 1990, com a consolidação e expansão dos conjuntos habitacionais populares na Zona Norte, o crescimento e desenvolvimento da Zona Sul e o surgimento de novas centralidades urbanas em Natal, fora dos eixos dos serviços mais tradicionais da cidade (Ribeira, Cidade Alta e Alecrim), a avenida ganhou grande impulso, consolidando-se com serviços diversos em suas margens, bem como na sua área circunvizinha. Sobre a diversidade dos serviços na avenida, Mello (2008, p. 84) nos mostra que

Hoje, a avenida se consagra no setor de serviços de autopeças, revendedoras de automóveis usados, madeireiras, lojas de material de construção, postos de gasolina, um shoppingcenter de grande porte, pequenos comércios e algumas residências. Portanto, uma grande variedade de equipamentos, ou seja, uma grande diversidade de usos.

Desta forma, como projeto viário, a Bernardo Vieira nasce de uma necessidade ligada à abolição das distâncias entre as várias regiões da cidade, pelo controle da velocidade, por meio da construção de via de trânsito rápido - semi-expressa. Assim, a velha avenida firmou-se, desde o início, como importante artéria comercial e de serviços em Natal, fato consolidado nos dias atuais. Na realidade, o Plano de Sistematização de Natal ao contemplar várias avenidas, a exemplo desta, viria a viabilizar a extensão da "mancha terciária" da cidade, com a criação de áreas passíveis de serem incorporadas pelo mercado imobiliário com a finalidade de construir espaços os mais variados e modernos, destinados aos serviços. Assim, esse fato se tornou mais concreto a partir dos anos de 1980, com o desenvolvimento e crescimento socioespacial verificado na cidade na qual destacamos a referida avenida.

A Avenida Bernardo Vieira concentra, na atualidade, um excessivo fluxo de veículos, principalmente, de passagem, uma vez que cerca de 35\% dos itinerários das linhas de ônibus de todas as empresas operantes no município, trafegam no seu espaço físico (STTU, 2010). Nos últimos anos, essa avenida perdeu a sua fluidez com o aumento progressivo do tráfego acima de sua capacidade, aumentando, consideravelmente, os conflitos entre os transportes coletivos de passageiros e os veículos particulares (Quadros 1 e 2 em anexo).

Observando-se os quadros, notamos o considerável número de linhas que trafegam pela Avenida Bernardo Vieira, com destinos variados, mostrando a importância desta via para toda a cidade bem como para a sua Região Metropolitana. Seu papel de articuladora de fluxo de pessoas e de veículos, também, se torna mais evidente quando, segundo dados da STTU, o número de veículos particulares circulando na avenida por dia, é da ordem de 55.000. Além da

\footnotetext{
${ }^{2}$ Referimo-nos aos bairros que iam se formando e consolidando na cidade tais como: Lagoa Seca, Dix Sep-Rosado, Quintas e Alecrim.
} 
frota efetiva de 688 ônibus circulando diariamente nesta avenida, existe uma frota reserva de 126 ônibus, totalizando 714 coletivos ao todo (STTU, 2010).

Nesse sentido, com o crescimento e os problemas ali verificados, no ano de 2007 a PMN (Prefeitura Municipal de Natal), via STTU (Secretaria de Transportes e Trânsito Urbano), dentro das políticas públicas urbanas de transportes e, buscando alternativas que viesse a amenizá-los, realizou dois grandes projetos: o Projeto de Geometria Viária que objetivou o nivelamento das calçadas e o Projeto da Rota Acessiva, este, objetivando, entre outros aspectos, dar uma maior mobilidade ao sistema de transporte coletivo e conforto aos usuários. Assim, em 2006, a ARCO Engenharia, empresa vencedora da licitação para a execução dos dois projetos - o projeto de geometria viária e o da rota acessiva - iniciou os seus trabalhos, no mesmo ano, finalizando-o em $2008^{3}$.

O primeiro projeto visou amenizar a problemática dos congestionamentos de veículos na avenida. Nesse caso particular, a solução apontada pelos estudiosos para a área foi o de investir no transporte público. Sob esta ótica, a PMN optou pela implantação da faixa exclusiva para ônibus, nessa que é uma das maiores e mais movimentada avenida da cidade. Portanto, a implantação da faixa exclusiva para ônibus, teve como objetivo mudar o perfil do transporte urbano na capital, dentro do conceito de mobilidade urbana sustentável, com a valorização dos usuários de transporte público de massa, obedecendo aos critérios das políticas públicas urbanas de transporte do município (PLANO DIRETOR DE NATAL, Lei complementar № 082, 2007).

Entrementes, no âmbito municipal foi criada a SEMOB, a qual tinha como objetivo maior a formulação e implementação de políticas de mobilidade urbana sustentáveis, entendidas como a reunião de políticas de transporte e de circulação, integradas à política de desenvolvimento urbano, com a finalidade de proporcionar o acesso amplo e democrático ao espaço urbano, priorizando os modos de transportes coletivos e os não motorizados, de forma segura, socialmente inclusiva e sustentável.

Neste sentido, a partir do que foi mencionado na supracitada política, foi realizada uma obra, que passou mais de um ano para ser concluída, cujo objetivo era melhorar o tráfego de veículos nos horários de pico, dando ênfase aos transportes públicos e procurando resolver os transtornos para motoristas e pedestres que por, ali, trafegam todos os dias. Segundo levantamentos da STTU, a quantidade de veículos dia que trafega nessa avenida é da ordem de 120 mil veículos em média, sendo 150 ônibus num intervalo de apenas uma hora. Segundo Carlos Azevedo, um dos engenheiros responsáveis pela obra, a cada mês, a cidade recebe, aproximadamente, cerca de 2.000 a 2.500 veículos novos, necessitando, dessa forma, de intervenções que venham a possibilitar a amenização dos congestionamentos, bem como diminuir o tempo das viagens do transporte público de passageiros (STTU, 2010).

Além disso, hoje, segundo dados da STTU, cerca de 650 mil usuários utilizam, diariamente, o transporte coletivo em Natal. Atualmente, dentro dos 3,5 km que sofreram intervenções, pela

\footnotetext{
${ }^{3}$ Segundo a STTU (2008), esta obra teve um valor de R\$ 4.156.003,74, dinheiro proveniente do Programa de Apoio ao Desenvolvimento Urbano de Municípios de Médio e Grande Porte, beneficiando um total de 120 famílias (STTU, 2008).
} 
qual passou a avenida podemos destacar: alargamento da pista existente em direção ao canteiro central, visando, entre outros aspectos, a ampliação e dedicação da faixa mais a esquerda para o tráfego exclusivo de transportes coletivos; demolição do canteiro central para implantação e pavimentação de faixa exclusiva para as paradas de ônibus; construção de plataformas para embarque e desembarque de passageiros; fechamento da abertura existente no canteiro central no cruzamento com a Rua dos Pegas; adequação semafórica, proibindo o sentido à esquerda no cruzamento com a Avenida Coronel Estevam; fechamento dos retornos no canteiro central ao longo do trecho de implantação do projeto; sinalização viária; instalação de iluminação pública nas plataformas de ônibus; relocação de postes de alta tensão e recapeamento das pistas existentes. As figuras abaixo ilustram as transformações pelas quais passou a Avenida Bernardo Vieira.

Segundo a STTU, a melhoria na malha viária contemplou outros benefícios como: a nova pavimentação e a renovação da sinalização vertical e horizontal; à implementação da "onda verde", com a sincronia de todos os semáforos, a exemplo do que já acontece nas avenidas Prudentes de Moraes e Hermes da Fonseca, permitindo aos motoristas trafegarem a uma velocidade média de $50 \mathrm{~km}$, encontrando todos os sinais abertos e na sua faixa exclusiva, fato que, segundo a STTU, diminui substancialmente as distâncias e o tempo gasto pelo usuário e os motoristas de ônibus, que têm essa avenida em seu itinerário diário. Em média, se gastava cerca de 30 minutos no corredor antes das modificações. Hoje, esse tempo caiu para 15 ou 20 minutos (STTU, 2010).

Essas transformações visavam amenizar os conflitos entre os ônibus e os veículos particulares foram amenizados, contribuindo, desta forma, para a redução do número de acidentes e congestionamentos em toda a avenida. Por outro lado, a instalação das plataformas no canteiro central da avenida não oferece nenhum tipo de perigo aos pedestres, uma vez que existem botoeiras e faixas de pedestres nos trechos que dão acesso às plataformas de embarque e desembarque.

Cada plataforma comporta até três ônibus, não sendo mais permitido o embarque ou desembarque dos usuários fora das mesmas. Esse fato contribuiu, de forma substancial, para a organização dos transportes de massa, naquele logradouro. Além disso, nos dois primeiros meses, enquanto a população não se acostumava às mudanças que ocorreram na Bernardo Vieira, foram disponibilizadas equipes da STTU em toda a extensão da avenida, com a finalidade de orientar os usuários. Outro fato digno de nota foi à proibição do estacionamento de veículos na avenida a partir das intervenções realizadas pela obra acima mencionada.

No que concerne ao Projeto Rota Acessiva, apenas, parte dele foi implementado, em virtude do mesmo ter logrado um orçamento de $\mathrm{R} \$ 1.300 .000$ (um milhão e trezentos mil reais), quantia esta que, ainda, está sendo viabilizada pela STTU, junto aos órgãos ligados a esta secretaria. Como se trata de um projeto que prevê desapropriação de alguns estabelecimentos comerciais e de serviços para que seja executado da forma como foi planejado no projeto original, levou algum tempo tanto para se garantir o valor da obra, bem como as negociações dos atores diretamente envolvidos nessa questão (STTU, 2010). 
Assim, apenas as calçadas mais, diretamente, próximas às plataformas de embarque e desembarque de passageiros sofreram transformações, ou seja, foram niveladas e equipadas para facilitar a locomoção dos pedestres, incluindo os portadores de deficiência que precisam trafegar por esta área.

Todavia, as transformações ocorridas na avenida, via políticas públicas de transportes, vêm causando grande insatisfação por parte, principalmente, dos comerciantes da área. Estes alegam que desde a proibição do estacionamento dos veículos nas calçadas, em função da execução do segundo projeto na avenida, houve uma queda considerável nas vendas de todos que, ali, têm algum tipo de comércio e/ou serviços, ocasionando uma perda considerável dos consumidores.

Nesse sentido, na tentativa de elucidar as consequências trazidas por esse tipo de política pública de transporte, implementada nesta área da cidade, aplicamos formulários com os diferentes atores sociais, diretamente, envolvidos nesta problemática, ou seja, os comerciantes, os motoristas de ônibus, de carros particulares e os usuários dos transportes coletivos que trafegam na avenida, a fim de obtermos um diagnóstico mais verdadeiro, no que tange ao discurso do Estado, via PMN e a realidade de quem circula, diariamente, na Bernardo Vieira, sentindo de perto todas as consequências, sejam elas negativas ou positivas a partir das transformações por que esta passou.

Nesta perspectiva, aplicamos um formulário contendo 2 questões (uma fechada e outra aberta) para estes atores. Todavia, tanto para os comerciantes como para os motoristas de ônibus, adotamos como forma de amostragem, um percentual de $20 \%$ de formulários por serviços, totalizando 104 formulários. Para os motoristas de ônibus, esse percentual de $20 \%$ foi aplicado, levando-se em consideração a frota de veículos, abrangendo 168 ônibus/dia, em 20 linhas, das 7 empresas que trafegam na avenida, totalizando 36 formulários.

Para os motoristas de carros particulares, o formulário foi aplicado junto a 200 pessoas, nos 15 postos de gasolina existentes na avenida, em ambos os lados. Para os usuários de transportes coletivos, também, aplicamos 200 formulários no conjunto das plataformas de embarque e desembarque existentes ao longo da avenida. O resultado das questões levantadas a todos os atores envolvidos nesse processo, nos mostrou o seguinte quadro da atual situação da Avenida Bernardo Vieira, no que se refere às transformações implementadas pela STTU, via PMN (Tabela 1).

Com base na tabela, podemos constatar que $97,1 \%$ dos comerciantes da avenida não ficaram satisfeitos com as transformações ali ocorridas, alegando, principalmente, que a falta de estacionamentos tem prejudicado de forma substancial os seus negócios e, consequentemente, perda de consumidores. Outra característica apontada diz respeito à falta de segurança, pois, os assaltos na avenida são constantes. No entanto, um percentual de $2,9 \%$ afirmou que foram boas as recentes transformações, alegando que a avenida ficara mais organizada, mais sinalizada e que diminuíra os acidentes nela registrados.

Constatamos também que um percentual de 2,9\% afirmou que foram boas as recentes transformações, alegando que a avenida ficara mais organizada, mais sinalizada e que diminuíra 
os acidentes nela registrados. A tabela, também, nos mostra que $100 \%$ dos motoristas de ônibus aprovaram as transformações ali ocorridas alegando, entre outros aspectos, que diminuíra substancialmente o tempo no itinerário por eles almejado na avenida, bem como o tráfego para os transportes coletivos ficara mais organizado.

Todavia, para a maioria dos motoristas de veículos particulares $(86,6 \%)$, as transformações não foram bem aceitas, porquanto, para estes houve um aumento no tempo das viagens na avenida, como também a falta de retornos tem causado muitos transtornos. Os motoristas afirmaram ainda que a via ficara muito estreita para seus veículos com a implementação do corredor viário. Entretanto, um percentual de $14 \%$ aprovou tais transformações. Entre as razões apontadas destacamos as seguintes: a avenida ficara mais organizada, menos perigosa e mais bonita do ponto de vista paisagístico (pesquisa de campo: 2009-2010).

No que concerne aos usuários de transportes coletivos que, ali, trafegam $75 \%$ afirmaram que tais transformações foram positivas porque a avenida ficara mais organizada, havendo, também, uma substancial diminuição no tempo dos percursos por eles realizados. Entretanto, $25 \%$ ressaltaram que estas não haviam surtido os efeitos esperados, pois, a avenida ficara mais lenta, provocando com isso, um grande engarrafamento, o que para eles era motivo de grandes aborrecimentos.

Contudo, consideramos que a atual situação, na qual a Avenida Bernardo Vieira se encontra, é muito preocupante, sobretudo, no que tange ao comércio e serviços, ali, instalados. É notório na Bernardo Vieira, além da perda de consumidores, o fechamento de muitas lojas e a transferência destas para outras áreas da cidade, onde há possibilidade de vendas para os lojistas. Segundo o Sindicato dos Lojistas de Natal (SLN), houve desde as reformas implantadas na Bernardo Vieira, uma queda nas vendas da ordem de aproximadamente $30 \%$, causando prejuízo na economia da área, bem como para a cidade como um todo, pois, essa diminuição nas vendas implicou na demissão de empregados. Registramos, ainda, que após a conclusão dos projetos para a avenida, qualquer estabelecimento comercial que pretenda, ali, instalar-se tem que ter, segundo a STTU, seu próprio estacionamento, fato completamente impossível dada às condições em que a Bernardo Vieira se encontra na atualidade (SLN, 2010).

\section{CONSIDERAÇÕES FINAIS}

Pelo exposto, depreendemos que a participação em todo e qualquer projeto que venha a ser implementado na área urbana, deve ser objeto de discussões e debates junto à população. Só desta forma, através de muito diálogo e participação conjunta de todos os envolvidos e interessados em políticas públicas urbanas, principalmente, as de transportes, podemos contemplar e beneficiar a sociedade de modo adequado e consensual. Passado dois anos da conclusão das reformas implementadas na avenida, muitos são os problemas ali encontrados, uma vez que os dois anos do novo sistema de funcionamento da Avenida Bernardo Vieira não 
mudaram em nada a opinião dos moradores e comerciantes do entorno da via, que desde a sua inauguração em 2008 reclamam da reformulação do local.

O desgaste do tempo, aliado ao vandalismo, tem prejudicado a estrutura da passarela e das paradas de ônibus. Os canteiros estão cada dia acumulando mais lixo, o asfalto segue irregular, sem contar os inúmeros buracos existentes ao longo dos seus $3,5 \mathrm{~km}$ de extensão da via. Para quem transita de carro, além desses problemas, também é preciso ter paciência para passar pelos 16 semáforos não sincronizados. Já os pedestres precisam torcer para não estar entre as próximas vítimas dos assaltantes que circulam pelas paradas dia e noite. Assim, constatamos que este é o quadro atual em que se encontra uma das mais importantes avenidas da capital potiguar.

\section{ANEXO}

Quadro 1: Número de linhas e itinerários dos ônibus que trafegam na Av. Bernardo Vieira

\begin{tabular}{|c|c|}
\hline LINHAS & INTINERÁRIOS \\
\hline 83 & Felipe Camarão/Ponta Negra \\
\hline 30 & Felipe Camarão/Pirangi via Campus Candelária \\
\hline 31 & Felipe Camarão/Pirangi via Campus Candelária \\
\hline 63 & Felipe Camarão/Campus Mirassol \\
\hline 02 & Gramoré/Mirassol/Campus/Nova República \\
\hline 04 & Amarante via Campus/Mirassol \\
\hline 08 & Redinha/Mirassol via Campus \\
\hline 18 & Bairro Nordeste/Campus \\
\hline 72 & Vale Dourado/Mirassol \\
\hline 76 & Felipe camarão/Parque das Dunas \\
\hline 77 & Parque dos Coqueiros/Mirassol via Campus \\
\hline 79 & Parque das Dunas/Mirassol via Campus \\
\hline 07 & Alvorada IV/ Ponta Negra \\
\hline 26 & Soledade I/Ponta Negra \\
\hline 29 & Soledade II/Viaduto de Ponta Negra via Nova Descoberta \\
\hline 29 & Soledade II/Viaduto de Ponta Negra via Nova Descoberta \\
\hline 46 & Ribeira/Ponta Negra via Praça Cívica \\
\hline 73 & Santarém/Ponta Negra via Av. Itapetinga \\
\hline 50 & Serrambi/Conjunto santa Catarina \\
\hline 03 & Nova Natal/Campus/Mirassol \\
\hline 28 & Nova Natal/IFRN \\
\hline TOTAL & 20 \\
\hline
\end{tabular}

Quadro 2: Quantitativo de viagens por empresa.

\begin{tabular}{|c|c|c|c|}
\hline EMPRESAS & DIAS ÚTEIS & SÁBADOS & DOM/FERIADOS \\
\hline Viação Cidade das Dunas LTDA & 272 & 205 & 191 \\
\hline Auto Ônibus Santa Maria & 1096 & 936 & 711 \\
\hline Empresas de Transportes Guanabara & 1507 & 1303 & 416 \\
\hline Emp. Transp. Nossa Senhora da Conceição & 694 & 585 & 416 \\
\hline Emp. Transp. Nossa Senhora da Conceição & 694 & 585 & 416 \\
\hline Reunidas Transportes Urbanos LTDA & 793 & 672 & 597 \\
\hline Viação Riograndense LTDA & 176 & 120 & 99 \\
\hline Transflor LTDA & 363 & 260 & 173 \\
\hline Total de Viagens & 4901 & 4082 & 3171 \\
\hline
\end{tabular}

Tabela 1: Opinião dos principais atores diretamente envolvidos na Av. Bernardo Vieira 


\begin{tabular}{|c|c|c|c|c|}
\hline Entrevistados & Sim (\%) & Não (\%) & Respostas positivas & Respostas negativas \\
\hline Comerciantes & 2,9 & 97,1 & $\begin{array}{l}\text { Avenida mais } \\
\text { organizada/mais } \\
\text { sinalizada }\end{array}$ & $\begin{array}{c}\text { Falta de } \\
\text { estacionamento/Falta } \\
\text { de segurança }\end{array}$ \\
\hline Motoristas de ônibus & 100 & - & $\begin{array}{c}\text { Diminuição no tempo do } \\
\text { percurso/Tráfego mais } \\
\text { organizado }\end{array}$ & - \\
\hline $\begin{array}{c}\text { Motoristas de veículos } \\
\text { particulares }\end{array}$ & 86 & 14 & $\begin{array}{c}\text { Avenida mais } \\
\text { organizada/menos } \\
\text { perigosa }\end{array}$ & $\begin{array}{c}\text { Aumento no tempo das } \\
\text { viagens/Falta de } \\
\text { retornos }\end{array}$ \\
\hline $\begin{array}{l}\text { Usuários de transportes } \\
\text { coletivos }\end{array}$ & 75 & 25 & $\begin{array}{c}\text { Avenida mais } \\
\text { organizada/diminuição } \\
\text { no percurso }\end{array}$ & $\begin{array}{c}\text { Avenida mais } \\
\text { lenta/Aumento dos } \\
\text { engarrafamentos }\end{array}$ \\
\hline
\end{tabular}

\section{REFERÊNCIAS}

LIMA, Pedro. Saneamento e modernização em Natal: Januário Cicco, 1920. Natal: Sebo Vermelho, 2003.

MELLO, Erick de Santana. Mobilidade Urbana Sustentável em Projetos estruturantes: análise urbanística do corredor de transporte da Avenida Bernardo Vieira. Dissertação (mestrado); Programa de Pós-Graduação em Arquitetura e Urbanismo, UFRN, Natal, 2008.

PLANO DIRETOR DE NATAL. Lei Complementar no 082, de 21 de junho de 2007. Título IV - da política de mobilidade urbana; artigos 57, 58, 59.

SECRETARIA DE TRANSPORTES E TRÂNSITO URBANOS - STTU. Dados da Av. Bernardo Vieira. Disponível em: <http://www.natal.rn.gov.br/sttu/>. Acesso em: 20 de maio 2010.

Dados da Av. Bernardo Vieira. Disponível em: <http://www.natal.rn.gov.br/sttu/>. Acesso em: 03 de agosto 2008.

SINDICATO DOS LOJISTAS DE NATAL (SLN). Breviário e perfil dos serviços em Natal. Documento original, 2010. 